\title{
Acúmulo de nutrientes por três cultivares de alface cultivadas em condi- ções do Semi-Árido
}

\author{
Leilson C Grangeiro; Kamargo R da Costa; Maria Aparecida de Medeiros; Alessandra M Salviano; \\ Maria Zuleide de Negreiros; Francisco Bezerra Neto; Stênio L de Oliveira \\ UFERSA, Dep ${ }^{\text {to }}$. Ciências Vegetais, C. Postal 137, 59625-900 Mossoró-RN; E-mail: leilson@ufersa.edu.br
}

\section{RESUMO}

O presente trabalho teve como objetivo determinar o acúmulo de nutrientes em cultivares de alface cultivadas em condições do semi-árido. O experimento foi conduzido em área experimental da Universidade Federal Rural do Semi-Árido em solo classificado como Argissolo Vermelho-Amarelo. O delineamento experimental utilizado foi em blocos casualizados completos em esquema fatorial 3 x 5 com quatro repetições. Os tratamentos resultaram da combinação de três cultivares de alface (Babá de Verão, Tainá e Verônica) e cinco épocas de coletas $(7,12,17,22$ e 27 dias após transplantio DAT). A máxima produção de matéria seca foi obtida aos 27 DAT, sendo de 8,9;6,9 e 6,4 $\mathrm{g}_{\text {planta }}{ }^{-1}$, respectivamente para as cultivares Babá de Verão, Tainá e Verônica. O período de maior demanda para $\mathrm{N}, \mathrm{P}, \mathrm{K}$ e Mg foi de 22 a 27 DAT e para Ca de 17 a 22 DAT, em todas as cultivares. A ordem decrescente dos nutrientes acumulados pelas cultivares de alface foi: $\mathrm{K}, \mathrm{N}, \mathrm{P}, \mathrm{Mg}$ e Ca.

Palavras-chave: Lactuca sativa L., nutrição de plantas, crescimento.

\begin{abstract}
Accumulation of nutrients by three lettuce cultivars grown under Semi-arid conditions

The objective of this work was to determine the accumulation of nutrients by lettuce cultivars in conditions of Semi-arid. The experiment was carried in the field of University Federal Rural do Semi-Árido, in Mossoró, Rio Grande do North State, Brazil, in soil Alfissol. The experimental design was of randomized complete blocks, with four replications, in a 3 x 5 factorial scheme, being evaluated the cultivars of lettuce: Babá de Verão, Tainá and Verônica and sampling times 7, 12, 17, 22 and 27 days after transplanting (DAT). The maximum accumulation of dry mass occurred at 27 DAT, being of $8.9 ; 6.9$ and $6.4 \mathrm{~g} / \mathrm{plant}$, respectively to cultivars Baby de Verão, Tainá and Verônica. The period of larger demand for N, P, K and $\mathrm{Mg}$ occurred from 22 to 27 DAT and for Ca of 17 the 22 DAT in all to cultivars. The nutrients in decreasing order of accumulation by the lettuce cultivars were: $\mathrm{K}, \mathrm{N}, \mathrm{P}, \mathrm{Mg}$ e Ca.
\end{abstract}

Keywords: Lactuca sativa L., plant nutrition, growth.

(Recebido para publicação em 31 de agosto de 2005; aceito em 5 de junho de 2006)

A alface (Lactuca sativa L.) é considerada a hortaliça folhosa mais importante na alimentação do brasileiro, o que assegura à cultura expressiva importância econômica. No Brasil, são, aproximadamente, $30 \mathrm{mil}$ hectares cultivados com alface, sendo responsável pela geração de $60 \mathrm{mil}$ empregos diretos. Originária de clima temperado, a sua adaptação, em regiões de temperatura elevada, tem gerado obstáculos ao seu crescimento e desenvolvimento, impedindo que a cultura expresse todo o seu potencial genético. Nestas condições, ocorre redução do ciclo da cultura, comprometendo sua produção, devido à aceleração do metabolismo da planta e, conseqüentemente, a antecipação da fase reprodutiva (Makishima, 1992; Setúbal \& Silva, 1992).

No Rio Grande do Norte, a produção da alface é baixa quando comparada com outras regiões do país, não atendendo com isso, a sua demanda interna. Os métodos de produção existentes são rudimentares e na maioria das vezes, não correspondem às expectativas de produtividades esperadas. Dentre os fatores que estão associados a estes baixos rendimentos, destacam-se o reduzido nível de tecnologia, falta de cultivares adaptadas às altas temperaturas e luminosidade e informações técnicas sobre o manejo desta cultura nessas condições, tendo em vista que as informações utilizadas, são adaptações do cultivo da alface em outras regiões.

O conhecimento da quantidade de nutrientes acumulada na planta, em cada estádio de desenvolvimento, fornece informações importantes que podem auxiliar no programa de adubação das culturas. É necessário ter consciência, no entanto, que as curvas de absorção refletem o que a planta necessita, e não o que deveria ser aplicado, uma vez que a eficiência de aproveitamento dos nutrientes é variável segundo as condições climáticas, o tipo de solo, o sistema de irrigação, o sistema de manejo, entre outros fatores. De modo mais efetivo, essas curvas auxiliam no programa de adubação, principalmente na quantidade dos nutrientes que devem ser aplicados nos distintos estádios fisiológicos da cultura (Villas Bôas, 2001).

Com relação à alface, já existem atualmente, no Brasil informações de pesquisa a respeito do crescimento e acúmulo de nutrientes em diferentes cultivares. Entretanto, os mesmos foram realizados em regiões de clima mais ameno (Radin et al., 2004), ou em condições de cultivo protegido (Lopes et al. 2003; Menezes Júnior et al., 2004), sem aplicação prática naquelas regiões que cultivam alface, em condições de altas temperatura e luminosidade.

Nesse contexto, o presente trabalho teve como objetivo determinar o acúmulo de nutrientes em diferentes cultivares de alface, cultivadas em condições do Semi-Árido.

\section{MATERIAL E MÉTODOS}

O experimento foi realizado na horta da Universidade Federal Rural do 
Semi-Árido em Mossoró, de setembro a outubro de 2004, em solo classificado como Argissolo Vermelho-Amarelo eutrófico. Amostras de solo foram retiradas da área experimental, cuja análise química, mostrou os seguintes resultados: $\mathrm{pH}$ (água) $=7,9 ; \mathrm{P}=157 \mathrm{mg} \mathrm{dm}^{-3}$; $\mathrm{K}=0,3 \mathrm{cmol}_{\mathrm{c}} \mathrm{dm}^{-3} ; \mathrm{Ca}=3,2 \mathrm{cmol}_{\mathrm{c}} \mathrm{dm}^{-3}$, $\mathrm{Na}=0,32 \mathrm{cmol}_{\mathrm{c}} \mathrm{dm}^{-3} ; \mathrm{Mg}=1,0 \mathrm{cmol}_{\mathrm{c}}$ $\mathrm{dm}^{-3} ; \mathrm{H}+\mathrm{Al}=1,0 \mathrm{cmol}_{\mathrm{c}} \mathrm{dm}^{-3} ; \mathrm{S}=4,8$ $\mathrm{cmol}_{\mathrm{c}} \mathrm{dm}^{-3} ; \mathrm{T}=5,82 \mathrm{cmol}_{\mathrm{c}} \mathrm{dm}^{-3} \mathrm{e} \mathrm{V}=$ $82,8 \%$.

O município de Mossoró está situado a $18 \mathrm{~m}$ de altitude, a $5^{\circ} 11$ ' de latitude sul e $37^{\circ} 20^{\prime}$ de longitude oeste. O clima da região, segundo a classificação de Köppen, é BSwh', isto é, seco e muito quente, com duas estações climáticas: uma seca que vai geralmente de junho a janeiro, e outra chuvosa, de fevereiro a maio, apresentando temperatura média anual de $27,4^{\circ} \mathrm{C}$, precipitação pluviométrica anual irregular com média de $673 \mathrm{~mm}$, umidade relativa de $68,9 \%$ e luminosidade de 241,7 h mês ${ }^{-1}$. Durante a condução do experimento a temperatura média diurna foi de $28,6^{\circ}$ C, a umidade relativa de $60,1 \%$ e insolação de 10,4 horas diárias.

O delineamento experimental utilizado foi em blocos casualizados em esquema fatorial 3 x 5 com quatro repetições. Os tratamentos resultaram da combinação de três cultivares de alface (Babá de Verão, Tainá e Verônica) e cinco épocas de coletas $(7,12,17,22$ e 27 dias após o transplantio - DAT). Em cada época foram coletadas seis plantas por repetição.

A semeadura foi realizada em bandejas de poliestireno expandido com 128 células, preenchidas com um substrato comercial, utilizando-se três a quatro sementes por célula. Após a germinação, realizou-se o desbaste, deixandose uma plântula por célula. O transplantio foi efetuado 20 dias após a semeadura, quando as mudas apresentavam de quatro a cinco folhas definitivas, no espaçamento de $0,20 \times 0,20 \mathrm{~m}$.

As adubações foram realizadas com base na análise do solo e recomendação de Cavalcanti (1998), sendo aplicado em pré-plantio $40 \mathrm{t} \mathrm{ha}^{-1}$ de esterco bovino curtido, $40 \mathrm{~kg} \mathrm{ha}^{-1} \mathrm{de} \mathrm{N}$, na forma de uréia, $60 \mathrm{~kg} \mathrm{ha}^{-1}$ de $\mathrm{P}_{2} \mathrm{O}_{5}$ na forma de superfosfato simples e $30 \mathrm{~kg} \mathrm{ha}^{-1} \mathrm{de}$

Tabela 1. Produtividade das cultivares de alface. Mossoró, UFERSA, 2005.

\begin{tabular}{lc}
\hline Cultivares & Produtividade $\left(\mathbf{t ~ h a}^{-1}\right)$ \\
\hline Babá de Verão & 24,6 a \\
Tainá & 21,8 a \\
Verônica & $20,8 \mathrm{a}$ \\
\hline C.V.(\%) & 14,5 \\
\hline
\end{tabular}

Médias seguidas pela mesma letra na coluna não diferem significativamente entre pelo teste de Tukey ao Tukey ao nível de 5\% de probabilidade.

$\mathrm{K}_{2} \mathrm{O}$, na forma de cloreto de potássio. Foi efetuada uma adubação nitrogenada em cobertura, aos quinze dias após o transplantio, com $40 \mathrm{~kg} \mathrm{ha}^{-1}$ de $\mathrm{N}$, na forma de uréia.

Após cada coleta, as plantas foram levadas ao Laboratório de Pós-colheita do Departamento de Ciências Vegetais, lavadas e colocadas em estufa com circulação forçada de ar à temperatura de $65^{\circ} \mathrm{C}$ por um período de $36 \mathrm{~h}$, quando se atingiu massa constante. Em função da quantidade de massa seca das amostras, determinou-se o acúmulo da parte aérea (caule + folha) em cada época de coleta, sendo os resultados expressos em g planta ${ }^{-1}$. Em seguida, as amostras foram processadas em moinho tipo Willey (peneira de $2 \mathrm{~mm}$ ) e acondicionadas em recipientes fechados.

Para análises dos teores de macronutrientes ( $\mathrm{P}, \mathrm{K}, \mathrm{Ca}$ e $\mathrm{Mg}$ ) foram pesadas amostras de $0,5 \mathrm{~g}$, mineralizadas por digestão nitroperclórica (Allan, 1969) e posterior determinação dos teores de cálcio e magnésio por complexometria (Embrapa, 1997); fósforo por colorimetria, utilizando o método do complexo fosfo-molíbdico em meio redutor, adaptado por Braga e Defelipo (1974) e potássio por fotometria de emissão de chama (Embrapa, 1997). O teor de nitrogênio foi determinado em $100 \mathrm{mg}$ de amostra digerida com ácido sulfúrico em presença de uma mistura de selênio em pó, sulfato de cobre e sulfato de potássio, pelo método Kjeldahl (Embrapa, 1997).

Com os valores de matéria seca e teores de N, P, K, Ca e Mg determinaram-se o acúmulo de massa seca e dos nutrientes em cada época de coleta.

Os dados obtidos foram submetidos às análises de variância utilizando-se o software ESTAT e análise de regressão com o software Tablecurve (Jandel Scientific, 1991).

\section{RESULTADOS E DISCUSSÃO}

\section{Acúmulo de matéria seca}

As cultivares de alface não diferiram estatisticamente entre si para a variável produtividade (Tabela 1), que foi aproximadamente o dobro da média da região, que é de $11 \mathrm{t} \mathrm{ha}^{-1}$. Segundo Ramos (1995), a baixa produtividade observada na região deve-se a utilização de cultivares pouco adaptadas às temperaturas e luminosidade elevadas, como também a não adoção de práticas que visem minimizar os efeitos extremos da temperatura e da luminosidade local. Queiroga (2000) determinou produtividades superiores às obtidas neste trabalho com as cultivares Great Lakes (57,9 t ha-1), Verônica $\left(39,1 \mathrm{t} \mathrm{ha}^{-1}\right) \mathrm{e}$ Regina (46,9 t ha-1). Embora o experimento tenha sido realizado na mesma região, as maiores produtividades obtidas nesse trabalho foi provavelmente, devido ao período de condução do experimento, sendo que neste último, o experimento foi conduzido no primeiro semestre do ano, quando as temperaturas são mais amenas e foram utilizados telas de sombreamento durante a condução da cultura.

O crescimento da planta, expresso pelo acúmulo de matéria seca ao longo do ciclo, foi lento até 12 dias após o transplantio (DAT), intensificando-se depois. A produção estimada de massa seca total foi respectivamente de 8,9; 6,9 e 6,4 g planta $^{-1}$, para as cultivares Babá de Verão, Tainá e Verônica, obtidas aos 27 DAT (Figura 1). O maior acúmulo de matéria seca ocorreu no período compreendido entre 22 e 27 DAT, quando as taxas de incrementos foram de 1,06; 0,66 e 0,66 g planta $^{-1} \mathrm{dia}^{-1}$, na mesma ordem das cultivares citada anteriormente.

\section{Acúmulo de macronutrientes}

As taxas de acúmulo dos macronutrientes pela parte aérea das 

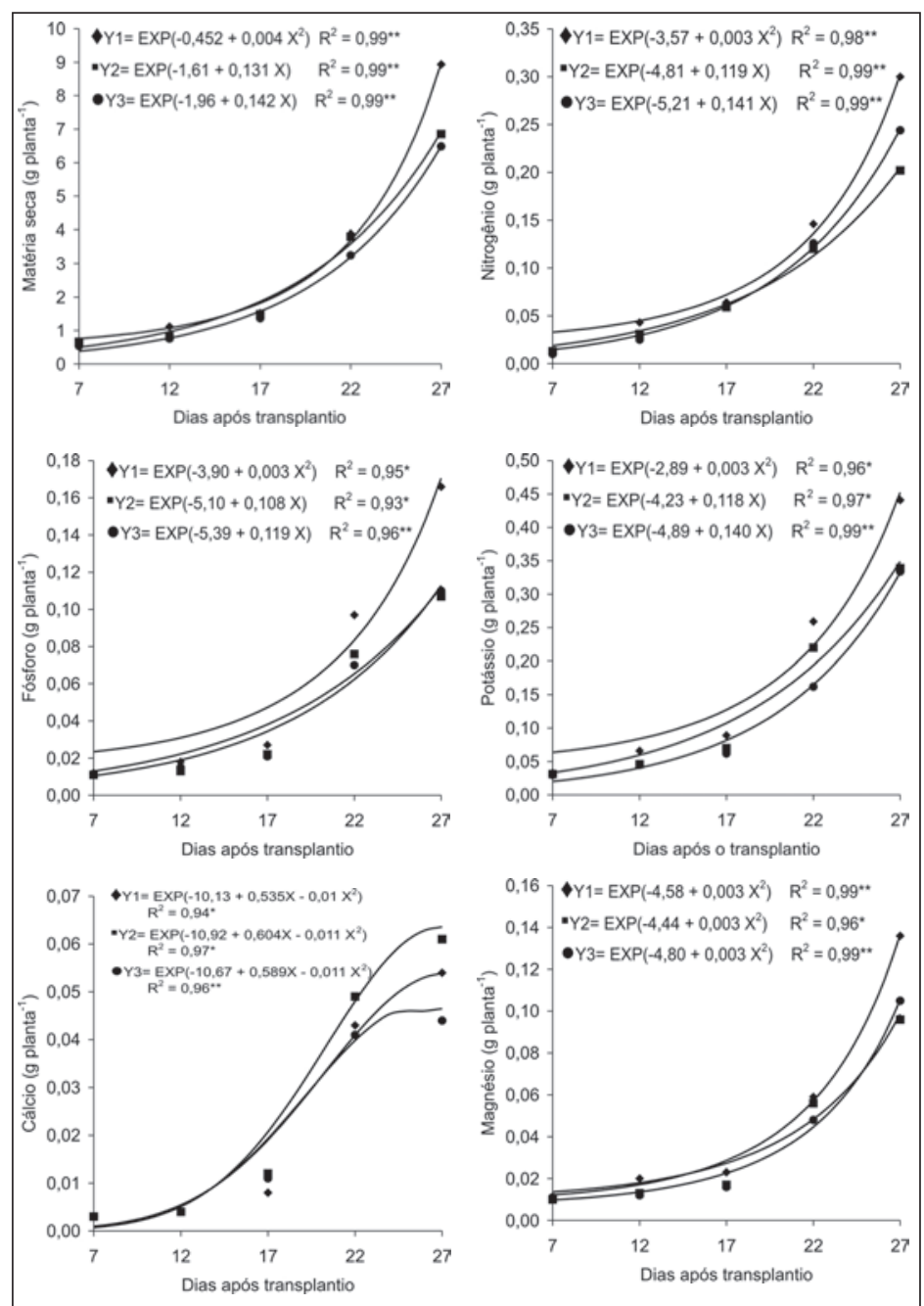

Figura 1. Acúmulo de matéria seca e de N, P, K, Ca e Mg na parte aérea das cultivares de alface, Babá de Verão (Y1), Tainá (Y2) e Verônica (Y3), aos 12, 17, 22 e 27 DAT. MossoróRN, UFERSA, 2005.

cultivares de alface foram baixas nos primeiros 12 DAT, devido o menor acúmulo de matéria seca. Após 12 DAT, houve um incremento, observando-se uma maior demanda para $\mathrm{N}, \mathrm{P}, \mathrm{K}$ e $\mathrm{Mg}$ no período de 22 a 27 DAT e para o Ca de 17 a 22 DAT. A ordem decrescente dos macronutrientes extraídos em todas as cultivares foi: $\mathrm{K}, \mathrm{N}, \mathrm{P}, \mathrm{Mg}$ e Ca. Apesar de absorverem quantidades relativamente pequenas de nutrientes, quando comparadas com outras culturas, devido ao seu ciclo curto (50 a 70 dias, em função de cultivares, épocas e locais de cul- tivo), a alface pode ser considerada como exigente em nutrientes, principalmente na fase final do ciclo (Katayama, 1993). do em maior quantidade pelas cultivares de alface, semelhantemente, ao observado em outros trabalhos (Fernandes et al.,1981; Garcia et al., 1982; Lopes et al., 2003). Os acúmulos máximos foram respectivamente de 0,$45 ; 0,35$ e $0,33 \mathrm{~g} \mathrm{planta}^{-1}$, para as cultivares Babá de Verão, Tainá e Verônica, com a maior demanda ocorrida no período de 22 a 27 DAT (Figura 1). Nesse período, o
O potássio foi o nutriente acumula- acúmulo de potássio correspondeu respectivamente, na mesma ordem das cultivares anteriormente citadas, a 51,1; 45,7 e $51,5 \%$ do total acumulado pelas mesmas até o final do ciclo.

O potássio, embora não faça parte de nenhum composto orgânico, desempenha importantes funções na planta como nas propriedades osmóticas, abertura e fechamento dos estômatos, fotossíntese, ativação enzimática, síntese de proteínas e transporte de carboidratos entre outros (Marschner, 1995). A aplicação de potássio na forma de cloreto, na dose de $113,8 \mathrm{~kg} \mathrm{ha}^{-1}$ em alface americana (cv. Lorca), proporcionou uma maior produção total e comercial (Mota et al., 2001).

As cultivares Babá de Verão, Verônica e Tainá acumularam respectivamente, 0,$30 ; 0,24$ e 0,20 g planta $^{-1}$ de N. A maior demanda ocorreu de 22 a 27 DAT, na época de maior acúmulo de massa seca na planta (Figura 1).

As quantidades de $\mathrm{N}$ acumuladas foram pequenas nos estádios iniciais, com incrementos médios de 0,002 ; 0,005 e 0,005 g planta dia $^{-1}$ no período de 5 a 12 DAT para as cultivares Babá de Verão, Tainá e Verônica respectivamente. Na fase de maior acúmulo (22 a 27 DAT), a taxa de incremento foi de 0,$03 ; 0,02$ e 0,02 g planta dia $^{-1}$, na mesma ordem das cultivares acima citadas (Figura 1). Assim como observado para matéria seca, a cultivar Babá de Verão também acumulou maior quantidade de nitrogênio.

Tendo em vista a cultura da alface ser composta basicamente de folhas, a mesma responde bem ao fornecimento de nitrogênio, nutriente que requer um manejo especial quanto à adubação, por ser de fácil lixiviação e pelo fato da cultura absorver maior quantidade na fase final do ciclo. A sua deficiência retarda o crescimento da planta, induz a má formação da cabeça e o amarelecimento das folhas mais velhas (Goto et al., 2001).

$\mathrm{O}$ fósforo, diferentemente do observado por Lopes et al. (2003) foi depois do $\mathrm{K}$ e $\mathrm{N}$ o nutriente de maior acúmulo nas três cultivares de alface. As cultivares Babá de Verão, Verônica e Tainá acumularam respectivamente, 0,$17 ; 0,11 \mathrm{e}$ $0,11 \mathrm{~g}_{\text {planta }^{-1}}$ de fósforo, com maior demanda no período de 22 a 27 DAT 
(Figura 1). De uma forma geral, as quantidades de fósforo exigidas pelas culturas são baixas, principalmente quando comparadas com o nitrogênio e potássio. Além de afetar o desenvolvimento da planta, o fósforo pode interferir no equilíbrio nutricional da cultura. A deficiência de fósforo em alface provoca atraso no crescimento das plantas e má formação da cabeça (Katayama, 1993). Em plantas muito novas, a deficiência desse nutriente pode provocar a morte (Weir \& Cresswell, 1993). Em alface americana (cv. Legacy), a utilização de fertilizantes fosfatados aumentou a produção, sendo o superfosfato simples superior ao termofosfato magnesiano, na dose de $617 \mathrm{~kg} \mathrm{ha}^{-1}$ de $\mathrm{P}_{2} \mathrm{O}_{5}$ (Mota et al., 2003).

O acúmulo de magnésio foi crescente em todas as cultivares de alface, atingindo o máximo aos 27 DAT. Os acúmulos máximos foram respectivamente de 0,$14 ; 0,10$ e 0,11 g planta $^{-1}$, para as cultivares Babá de Verão, Tainá e Verônica, com a maior demanda ocorrida no período de 22 a 27 DAT (Figura 1). Nesse período, o acúmulo de magnésio correspondeu respectivamente, na mesma ordem das cultivares anteriormente citadas, a 58, 52 e 58\% do total acumulado pelas mesmas até o final do ciclo.

As cultivares de alface Tainá, Babá de Verão e Verônica acumularam ao final do ciclo respectivamente 0,063 ; 0,054 e $0,046 \mathrm{~g}$ planta $^{-1}$ de cálcio, com maior demanda ocorrida no período de 17 a 22 DAT. Na etapa final do ciclo, a cultivar Verônica, mostrou diferentemente, das demais cultivares, uma estabilização no acúmulo de cálcio (Figura 1). O cálcio foi o nutriente de menor acúmulo, discordando dos resultados obtidos por Lopes et al. (2003) quando avaliaram diversas cultivares em cultivo hidropônico.

A principal função do cálcio na planta é manter a integridade da parede celular e o seu fornecimento inadequado é caracterizado pelo surgimento de necrose, principalmente nas extremidades das folhas em desenvolvimento. $\mathrm{Na}$ cultura da alface a deficiência de cálcio constitui-se em um dos principais problemas, pois é responsável pelo distúrbio fisiológico "queima dos bordos"
(Collier \& Tibbitts, 1982). Mesmo quando este nutriente encontra-se em níveis adequados no solo ou solução nutritiva o problema pode aparecer.

Na planta, o cálcio move-se com a água, sendo sua translocação e seu teor nos tecidos sujeitos à taxa de transpiração. Uma vez depositado, não apresenta redistribuição para outras partes da planta, sendo acumulado principalmente em tecidos com transpiração mais intensa. Nos órgãos que apresentam dificuldade para transpirar, como as folhas novas e internas da alface, o transporte do cálcio é dependente das condições ambientais que favoreçam o desenvolvimento da pressão radicular. Fatores que inibem o desenvolvimento da pressão radicular como seca, vento e alta salinidade promovem aparecimento de "queima dos bordos" (Collier \& Tibbitts, 1983).

Condições que favoreçam o rápido crescimento também aumentam a incidência. Desta forma, "queima dos bordos" desenvolve-se rapidamente em plantas expostas à alta intensidade luminosa e fotoperíodos mais longos (Gaudreau et al., 1994), alta temperatura do ar e níveis elevados de adubação nitrogenada (Brumm \& Schenk, 1993).

A utilização de curvas de acúmulo de nutrientes como um parâmetro para a recomendação de adubação, é uma boa indicação da necessidade de nutrientes em cada etapa do desenvolvimento da planta, indicando as quantidades de nutrientes absorvidas para se atingir certa produtividade, auxiliando assim no estabelecimento de um programa de fertilização para a cultura, facilitando principalmente o fracionamento das adubações. Entretanto, as mesmas não devem ser utilizadas isoladamente, pois outros fatores estão envolvidos e devem ser levados em consideração como: tipo de solo, condições climáticas, cultivares, manejo cultural e fertilizantes utilizados.

Considerando uma população de 250.0000 plantas ha $^{-1} \mathrm{e}$ as condições de elevada temperatura e luminosidade em que foram cultivadas as cultivares de alface, para as produtividades apresentadas pelas mesmas, a extração de nutrientes em $\mathrm{kg} \mathrm{ha}^{-1}$ foi: Babá de verão: $75 \mathrm{~kg} \mathrm{ha}^{-1}$ de $\mathrm{N} ; 42,5 \mathrm{~kg} \mathrm{ha}^{-1}$ de P; 112,5 $\mathrm{kg} \mathrm{ha}^{-1}$ de $\mathrm{K} ; 13,5 \mathrm{~kg} \mathrm{ha}^{-1}$ de Ca e $35 \mathrm{~kg}$ ha ${ }^{-1}$ de Mg; Tainá: $50 \mathrm{~kg} \mathrm{ha}^{-1} \mathrm{de} \mathrm{N} ; 27,5$ $\mathrm{kg} \mathrm{ha}^{-1}$ de P; $87,5 \mathrm{~kg} \mathrm{ha}^{-1}$ de $\mathrm{K} ; 15,7 \mathrm{~kg}$ ha $^{-1}$ de Ca e $25 \mathrm{~kg} \mathrm{ha}^{-1}$ de $\mathrm{Mg}$; Verônica: $60 \mathrm{~kg} \mathrm{ha}^{-1}$ de $\mathrm{N} ; 27,5 \mathrm{~kg} \mathrm{ha}^{-1}$ de P; 82,5 $\mathrm{kg} \mathrm{ha}^{-1}$ de $\mathrm{K} ; 11,5 \mathrm{~kg} \mathrm{ha}^{-1}$ de Ca e 27,5 $\mathrm{kg} \mathrm{ha}^{-1}$ de Mg.

Portanto, no programa de adubação realizado para a cultura da alface na região, considerando os níveis de produtividade obtidos e as referidas cultivares, as quantidades de N, P, K, Ca e Mg recomendadas não deverão ser menores aos extraídos pelas plantas no presente trabalho. Comparando esses valores com aqueles recomendados por Cavalcanti (1998), verifica-se que há necessidade de ajustes, pois os valores de $\mathrm{N}$ e $\mathrm{K}$ recomendados foram próximos dos extraídos pela cultura. As curvas de absorção refletem o que a planta necessita, e não o que deve ser aplicado, assim deve-se considerar também a eficiência de aproveitamento dos nutrientes.

Conforme foi apresentado, as cultivares de alface tiveram um crescimento inicial lento, com pequeno acúmulo de nutrientes nos primeiros 12 dias, corroborando com as recomendações de adubação realizadas na região, onde recomendam que se faça a adubação de cobertura após 15 dias do transplantio. A ordem decrescente dos macronutrientes extraídos em todas as cultivares foi: $\mathrm{K}$, N, P, Mg e Ca.

\section{REFERÊNCIAS}

ALLAN JE. 1969. The preparation of agricultural samples for analysis by atomic absorption spechtrometry. Varian. Techtron, $15 \mathrm{p}$. (Bulletin, 12).

BRAGA JM, DEFELIPO BV. 1974. Determinação espectrofotométrica de fósforo em extratos de solos e plantas. Revista Ceres 113: 7385.

BRUMM I; SCHENK M. 1993. Influence of nitrogen supply on the ocurrence of calcium deficiency in field grown lettuce. Acta Horticulturae 339: 126-136.

CAVALCANTI FJA. 1998. Recomendações de adubação para o estado de Pernambuco $\left(2^{a}\right.$ aproximação). Recife: IPA, 198p.

COLLIER GF; TIBBITTS TW. 1982. Tipburn of lettuce. Horticultural Reviews 4: 49-65.

EMBRAPA.. 1997. Manual de métodos de análise de solo. 2. ed. Rio de Janeiro: Centro Nacional de Pesquisa de Solos. 212p.

FERNANDES PD; OLIVEIRA GD; HAAG HP. 1981. Absorção de macronutrientes pela cultura do alface. In: HAAG HP; MINAMI K. (eds). Nutrição mineral em hortaliças. Campinas: Fundação Cargill. p. 143-151. 
GARCIA LLC; HAAG HP; MINAMI K; DECHEN AR. 1982. Nutrição mineral de hortaliças. XLIX. Concentração e acúmulo de macronutrientes em alface (Lactuva sativa $\mathrm{L}$.) cv. Brasil 48 e Clause's Aurélia. Anais da Escola Superior de Agricultura "Luiz de Queiroz" 39: 455-84.

GAUDREAU L; CHARBONNEAU J; VÉZINA LP; GOSSELIN A. 1994. Photoperiod and photosynthetic photon flux influence growth and quality of greenhouse grown lettuce. HortScience 29: 1285-1289.

GOTO R; GUIMARÃES VF; ECHER MM. 2001. Aspectos fisiológicos e nutricionais no crescimento e desenvolvimento de plantas hortícolas. In: FOLEGATTI, M.V.; CASARINI, E.; BLANCO, F.F.; BRASIL, R.P.C. do; RESENDE, R.S. (Cood.) Fertirrigação: flores, frutas e hortaliças. Guaíba: Agropecuária. 2: 241-268.

JANDEL SCIENTIFIC. 1991. Table Curve: curve fitting software. Corte Madera, CA: Jandel Scientific. 280p.

KATAYAMA M. 1993. Nutrição e adubação de alface, chicória e almeirão. In: FERREIRA ME; CASTELLANE PD; CRUZ MCP. Nutrição e adubação de hortaliças. Piracicaba: Potafos. p. 141-148.
LOPES MC; FREIER M; MATTE JD; GÄRTNER M; FRANZENER G; CASIMIRO ELN; SEVIGNANI A. 2003. Acúmulo de nutrientes de alface em cultivo hidropônico no inverno. Horticultura Brasileira 21: 211-215.

MAKISHIMA N. 1992. Cultivo de hortaliças. Brasília: CNPH. 26p.

MARSCHNER H. 1995. Mineral nutrition of higher plants. San Diego: Academic Press. $889 \mathrm{p}$.

MENEZES JÚNIOR FOG; MARTINS SR; FERNANDES HS. 2004. Crescimento e avaliação nutricional da alface cultivada em "NFT" com soluções nutritivas de origem química e orgânica. Horticultura Brasileira 22: 632-637.

MOTA JH; SOUZA R J; SILVA EC;CARVALHO JG; YURI JE. 2001. Efeito do cloreto de potássio via fertirrigação na produção de alfaceamericana em cultivo protegido. Ciência e Agrotecnologia 25: 542-549.

MOTA JH; YURI JE; RESENDE GM; OLIVEIRA CM; SOUZA RJ; Silvio AC; FREITAS SAC; Juarez C. 2003. Rodrigues Júnior, J.C. Produção de alface americana em função da aplicação de doses e fontes de fósforo. Horticultura Brasileira 21: 621-622.
QUEIROGA RCF. 2000. Produção de alface em função de cultivares e tipos de telas de sombreamento nas condições de Mossoró-RN. Mossoró: ESAM. 28p. (Tese mestrado).

RADIN B; REISSER JÚNIOR C; MATZENAUER R; BERGAMASCHI H 2004. Crescimento de cultivares de alface conduzidas em estufa e a campo. Horticultura Brasileira 22: 178-181.

RAMOS JEL.. 1995. Sombreamento e tipos de recipientes na formação de mudas e produção de alface. Mossoró: ESAM. 53p. (Tese mestrado).

SETÚBAL JW; SILVAAMR. 1992. Avaliação do comportamento de alface de verão em condições de calor no município de Teresina-PI. Horticultura Brasileira 10: 69, (Resumo 127).

WEIR RG; CRESSWELL GC. 1993. Plant nutrient disorders 3. Vegetable crops. Sydney. $105 \mathrm{p}$.

VILLAS BÔAS RL. 2001. Doses de nitrogênio para pimentão aplicadas de forma convencional e através da fertirrigação. Botucatu: Universidade Estadual Paulista. 123p. (Tese livre docência). 